\title{
Erratum to: Study of Intra-Varietal Genetic Variability in Grapevine Cultivars by PCR-Derived Molecular Markers and Correlations with the Geographic Origins
}

\author{
Stefano Meneghetti • Angelo Costacurta • \\ Giacomo Morreale • Antonio Calò
}

Published online: 30 April 2011

(C) Springer Science+Business Media, LLC 2011

\section{Erratum to: Mol Biotechnol}

DOI 10.1007/s12033-011-9403-9

In the original manuscript, the legends for Figures 3 and 4 were reversed. The legend for Fig. 3 should read: "SAMPL digitalized electropherogram of 14 Malvasia nera di Brindisi/Lecce accessions using ALFexpress-II instrument. Genotype 1 (line 1, 1a, 1b, 1c) was used as internal reference to align the molecular profiles using the ALF-win software".
The legend for Fig. 4 should read: "Dendrogram based on Dice's Genetic Similarity (Coph. V. $=0.893$ ) of the 26 accessions of Malvasia nera di Brindisi/Lecce (Malvasia $n$. BR/LE) using AFLP, SAMPL, M-AFLP, and ISSR molecular markers that discriminated all accessions according to the two geographic provinces, Brindisi (samples from 1 to 13) and Lecce (samples from 14 to 26)".

The online version of the original article can be found under doi: 10.1007/s12033-011-9403-9.

S. Meneghetti $(\square) \cdot$ A. Costacurta $\cdot$ G. Morreale $\cdot$ A. Calò CRA-VIT Consiglio per la Ricerca e la Sperimentazione in Agricoltura-Centro di Ricerca per la Viticoltura, Viale XXVIII Aprile, 26-31015 Conegliano, TV, Italy

e-mail: stefano.meneghetti@entecra.it 